\title{
El dioniso de Hugo Mujica: una estética panteísta
}

\author{
Juan Esteban Londoño \\ Universität Hamburg \\ londonojesteban@gmail.com
}

Recibido: 20 - enero - 2018 / Aprobado: 18 - marzo - 2018

\section{Resumen}

El presente ensayo es un análisis del libro Dioniso. Eros creador y mistica pagana del escritor argentino Hugo Mujica, en el que se presenta la estética de su obra poética. Para ello se analizan elementso como la musicalidad, los referentes poéticos y filosóficos, la simbología, la estructura del libro y los personajes míticos que danzan y actúan en la obra. El libro es una visión de la vida, de lo erótico, de la mística, de la potencia creadora de autor argentino.

Palabras claves: Hugo Mujica, poética, Dioniso.

\section{Abstract}

This essay is an analysis of the book "Dioniso, Creator Eros and Pagan Mysticism" by the Argentine writer Hugo Mujica, in which the aesthetics of his poetic work is presented. For this, elements such as musicality, poetic and philosophical referents, symbology, the structure of the book and the mythical characters who dance and act in the work are analyzed. The book is a vision of life, of the erotic, of mysticism, of the creative power of an Argentine author.

Keywords: Hugo Mujica, poetic, Dionysus. 

$\mathrm{H}$

ugo Mujica canta en silencio. Lo hace incluso en sus ensayos. Como sucede en el libro Dioniso. Eros creador y mística pagana (2016), donde el escritor argentino revela sus convicciones estéticas a partir de la máscara de un dios amado por la poesía y la filosofía.

El ángulo desde el que escribe Mujica -y siempre lo hace poetizando- es el de una visión de la vida, donde los dioses son personificaciones de un arrollador devenir, de una erótica de la creatividad donde siempre puede acontecer algo nuevo.

El libro es místico en su acepción más pura. El término significaba en el mundo griego lo referente a los misterios (ta mystika), a las ceremonias en las que el iniciado participaba en el proceso de muerte y resurrección de un dios. En este caso, el dios de la creatividad.

He aquí nuestra lectura ensayística de este libro, tocada por la poesía y por el canto báquico.

\section{Música}

Dioniso se abre con un preludio, como en la música. El escritor no pretende elaborar una doctrina sobre el dios griego, sino cantar una rapsodia, como los antiguos videntes. De ahí que la mayoría de las referencias de este libro provengan de poetas y rapsodas antiguos, como Hesíodo, Homero y Eurípides, o traigan ecos de escritores más cercanos a nuestro tiempo (pero originarios en sus búsquedas), como Hölderlin y Nietzsche.

La manía dionisíaca llega con la música. La flauta y el tambor son los instrumentos para la invocación y la epifanía del misterio. La música y el movimiento se liberan en la manifestación artística que permite interpretar al mundo de una forma diferente y nueva.

"Soy lo que le está aconteciendo a la vida ahora, ahora que me acontece la vida; somos su creación si la creamos y la creamos si nos dejamos crear" (2016: 13). Esta es la trama del libro o, en otras palabras, la trama es Dioniso. En él y en su leyenda se personifican el brotar incesante, y también la procesión pagana que deambula por las ciudades incitando al baile y al desbordamiento.

\section{Nacimiento}

De Caos nace Gaia y en ella todo es brote. La madre de todo lo viviente porque ella es lo viviente que se vive. La diosa más fecunda, adorada por cosmovisiones diversas. Gaia es una plena raíz en expansión. Gaia está abierta a Urano, hijo y consorte, padre. La creación más sagrada conocerá desde el principio la sexualidad y el erotismo.

El escritor argentino recuenta la Teogonía y en ella está la vida principiando, la que no tiene una moralidad ni una ley más que sus propios movimientos. Esa es la tierra y de ella nace el hombre. El hombre como palabra, porque el hombre y la mujer, o lo humano, es lo nombrado de la vida de la tierra y lo que nombra, el ser nombre de sí mismo, el animal con lenguaje. 
Después aparece el dios, cuando es nombrado, o acontece en el acto de nombrar. Y llega gracias a la voz del sacerdote griego, el hierofante: "el que hace aparecer lo sagrado" en el reino de la palabra. Convoca a las almas a que elijan a su daimon, como símbolo de su existencia sagrada:

Cada uno, dice, escoge a su dios, se sitúa bajo esa imagen, se templa en su resplandor.

Cada dios es una elección, cada una un destino.

Una decisión

(2016:18).

Hugo Mujica elige a Dioniso. No solamente quiere narrar al dios extranjero o presentarlo en imágenes poéticas, sino también narrarse a sí ante sí, cantar en presencia de los oyentes la elección totémica: el dios de la creatividad. El motivo de la elección está acompañado por dos palabras que atraviesan la obra de este escritor y resaltan en el libro: la vitalidad y la creación. Dioniso es el dios del nacimiento, deseo de vida y voluntad de crear.

En su confesión poética, Mujica enfrenta a dueños de leyes religiosas que han dejado sedimentar nombres y conceptos y habla con una voz distinta. Dios ni siquiera es, sino que acontece; y en este acontecer nace, no una vez, nace siempre, a cada instante.

Dioniso entonces es la personificación de la creación. No tiene una existencia independiente de la anchura de su territorio mas su región es inabarcable: la creatividad del cosmos. Las huellas del fuego quedan sobre la roca el día después de un culto delirante. Cuando se adora a las huellas se cae en la idolatría del encierro. Dioniso es más bien una crisis, imagen del dios que pregunta, efigie de rupturas.

Creación y vida: "La vida es un acto creador o deja de ser vida" (2016: 21). Así de radical es la proclama de Mujica. Pero no la reducción de la creación a un taller artesanal, ni de la vida a una incubadora. La creación se da viviendo. Se crea no solamente en la techné, sino también en el acontecer.

Así como la cultura es el lugar del nacimiento del hombre desde sus entrañas animales, el mito es el lugar del nacimiento de la narrativa. $Y$ al narrarse, también el hombre nace. El mito es la poesía de las potencias de la naturaleza que irrumpen en la vida humana y toman una imagen sublimada y terrible de lo humano, de sus abismos y luces no alcanzadas, de sus chispas y el fuego inapagable. El contarlo da origen al humano. El hombre y la mujer se dan a luz narrando el origen alrededor de la hoguera.

\section{Panteísmo estético}

A diferencia de un pensamiento de unidad unificante, Mujica retorna a los dioses como diversidad y ruptura, o pluralidad del ser expandiéndose en corrientes y riachuelos para embeber la tierra. Diferente también a la concepción moderna de la natura- 
leza como un dispositivo, una fuente de energía o una montańa a explotar, Mujica la ve como fuente del asombro y por esto los griegos la sentían poblada de dioses, seres fantásticos de los que germinaban la belleza y la fuerza irracional de las pasiones: el amor y la guerra, el relámpago y la ley. Mujica sitúa a Dioniso como la experiencia de algunos que viven el acontecimiento desde la creatividad estética y la mística erótica.

El acontecimiento dionisíaco es un aquí y ahora de lo divino en lo telúrico. No un más allá sino una presencia pura. Sin un detrás, sin una eternidad sosteniendo al tiempo, pues lo eterno es el instante donde acaece todo, la luz de la totalidad en la parcialidad del rayo.

"El Dios de todas las cosas -quienquiera que fuese-, ya que algunos lo llaman Naturaleza”, señala Robert Graves a la divinidad indefinida (2017: 47). No está lejos del dios de Mujica en este libro, para quien la palabra clave es panteismo.

El panteísmo se vive con el cuerpo y se siente con las emociones, pero también se hace palabra en la medida en que teje mutualidad y apertura con todas las cosas y fundamenta una ética de solidaridad y simpatía con lo sintiente y lo sentido. En el panteísmo de Mujica, lo trascendente es la inmanencia y lo terrenal todo lo trasciende.

En este panteísmo estético también el vitalismo y la creatividad son dos fuentes de las que brota la paradoja de unidad y pluralidad. Una vida viviendo en el receptáculo de las vidas individuales conectadas al todo que también se está viviendo. Vida habitada por humanos y animales, por las plantas, sobre Gaia y bajo ella, siempre desde ella como un organismo viviente que a todos nos abarca, pero inabarcable e inacabado. Este habitar la Madre Tierra es el amor y la afirmación de la existencia como juego y combate, sin por qué ni para qué, sin distinciones.

Dioniso es la personificación de la fecundidad. Sus palabras van asociadas a los líquidos del placer: leche, miel y vino. La tierra es un retońo báquico:

La vida brota, es él: Dioniso brota, todo brote es él,

todo vitalidad es su vivencia

toda vivencia

su vida

(2016:116).

"Brotar" es uno de los verbos más caros para el poeta argentino. El brotar es a la tierra lo que el nacer es a la vida y el crear a la poesía. El estado constante de la tierra es su brotar. Su ser es la fecundidad. Este concepto toma en el último libro de $\mathrm{Mu}$ jica la máscara de Dioniso pero ya está presente desde sus primeros ensayos, como es el caso de Origen y destino, donde la naturaleza eclosiona, emerge y se despliega:

La esencia de la tierra se muestra en su brotar y crecer e, indesligablemente, se oculta en su permanecer y arraigar. Es por este aspecto de raíz, de esta coloración nocturna, que mirada a 
la ligera la tierra parecería carente de expresión, pero al contrario, es esa nocturnidad la que resguarda lo inagotable de la obra, la sombra en la cual se custodia un sentido que no extenuará ninguna significación ni extinguirá ningún mundo (2014 a: 56).

A esa vida que se vive y se crea Mujica la llama Dioniso. Y por eso cimienta una teogonía desde abajo, no desde la cabeza como la hermana Atenea, sino una teogonía emergente, ya que hasta dios nace de las entrañas de la tierra, de su apertura seminal. En Dioniso, todo es dios y dios es todo y cada cosa mientras danza.

Dioniso es la vida siendo sentido de sí misma:

dándose a sentir:

sintiéndose en cada vida

(2016: 100).

Pero también es una vida creada y creándose en la creatividad, nombrando el hay mediante la fabricación vital de nuevas experiencias y sus formas de expresarlas en el arte.

La particularidad de Dioniso que acentúa Mujica es la de la creatividad. Ella es un impulso vital, una avidez de ser. Como lo ha demostrado en su libro dedicado a la poética Lo naciente. Pensando el acto creador (2007), la característica por excelencia del ser humano, más allá de pensar, es la de crear. En esto se cifra la antropología de Mujica. Y su teología, si se puede decir, su discurso poético sobre lo divino, es la de un Dioniso creador y también creado, a quien se acoge en lo creado y se le crea en la creatividad, siempre abierto, nunca terminado:

el deseo erótico de plenitud:

el crear y crearse;

crear de la nada, en medio de la nada:

crear contra la nada

y crear para nada:

por el gozo de crear

(2016: 124).

Entre tanto el ser humano está asombrado, con la boca cerrada ante lo que produce maravilla: que todo fluya y sea. El ser y no la nada, sin por qué ni para qué. Y la respuesta es la del entusiasmo, llenarse de dios, sentirse pleno de existencia, cantar y contar, no solamente contemplar, sino también crear.

\section{Extranjero}

En la tercera parte de su libro, Mujica caracteriza a Dioniso como el dios extranjero. Y según cuenta la leyenda, Dioniso viajó por diferentes territorios llevando la alegría y la lucha a muerte. Hera, celosa ante el hijo de Zeus, lo enloqueció y lo destinó a vagar por el mundo, acompañado por su preceptor Sileno 
y un ejército salvaje de Sátiros y Ménades. Navegó rumbo a Egipto, llevando consigo el vino. Marchó junto a las amazonas contra los Titanes y triunfó sobre ellos. Llegó a la India y conquistó todo el país, al que enseñó el arte de la vinicultura, dotándolo también de leyes y fundando ciudades. Regresó a Asia Menor y Grecia, donde invadió poblaciones y enloqueció a reyes y nobles cuando no participaban de las orgías sagradas. Contrajo matrimonio con Ariadna, venció a Perseo y finalmente ascendió al Olimpo para sentarse a la derecha de Zeus, entre los doce grandes dioses.

En Las Bacantes, Penteo, quien no busca la armonía de los contrarios sino la armonía mediante la imposición de un contrario sobre el otro, ve a Dioniso como la ruptura y entiende en cada ruptura lo inaceptable:

Dicen que ha venido un cierto extranjero, un mago, un encantador, del país de Lidia, que lleva una melena larga y perfumada de bucles rubios, de rostro lascivo, con los atractivos de Afrodita en sus ojos. ¡Y éste anda de día y de noche fascinando a nuestras jóvenes con los ritos mistéricos del evohé! (Eurípides, 1998: 234-240).

Mujica interpreta al dios extranjero desde la interiorización de su figura en la condición humana. La lejanía de Dioniso es la que mantiene las puertas abiertas del Olimpo para que lo otro sea posible: la alteridad completa inserta dentro de la comunidad de los iguales. El dios-hombre-animal baila y alucina, tan cerca de su hermana, diosa de la razón y de la guerra, y tan distinto a ella y a todos los demás. Por esto, para Mujica, "Dioniso es la diferencia" (2016: 107).

Esta diferencia no es solo la de ser, sino también la de pensar y decir. Dioniso "es la heterodoxia" (2016: 109). Trae consigo el decir de los otros, los que no están, y también dice lo otro, la palabra del disenso y la interpretación alternativa. Mientras Penteo está atemorizado de que los cuerpos de las mujeres se humedezcan y desborden y olviden las labores del hogar, Dioniso las incita, las excita a liberarse. Dioniso trae la otra versión del mensaje espiritual: la sub-versión del cuerpo; incluso, la per-versión. Pues lo subversivo de un sistema religioso y cultural reside en sus subversiones sexuales.

Mujica ve en Dioniso el ícono que abre lo otro de la vida: "la vida en carne viva", y la dimensión de la oscuridad. Dioniso no encarna solo lo bello, también lo terrible. Lo sublime de su máscara no se limita al verbo ser, sino al desbordamiento del ser, con derivaciones que no pueden ser pensadas en términos morales, como la locura o la muerte.

Se hace notable en la interpretación que hace Mujica de Las Bacantes el poder que tiene el acontecer dionisíaco en el desajuste de lo cotidiano y las normas de la cultura. Dioniso es un salto de libertad o la alteridad en su expresión icónica. Por esto es lo sublime que, a diferencia de lo bello, no retiene sino que desborda y suelta, libera hacia toda desmesura. 


\section{Máscara}

Los griegos usaban máscaras en el teatro y en los funerales. Mediante el término prósopon se referían a lo que aparece ante los ojos de los otros y, por extensión, a la faz de los dioses.

Mujica emparenta a la máscara y a la persona humana porque la máscara es la representación de sí ante los demás. Pero hace la salvedad de que las máscaras de Dioniso no se llevaban puestas sino que se adoraban, pues la máscara es la vida misma, el rostro que se pone cada quién como armadura para enfrentar el combate, o como disfraz para danzar la fiesta.

"Dioniso no usa una máscara: la es" (2016: 138). Y en este sentido es máscara de sí y también de sus adoradores. La diferencia es que los adoradores sueñan que hay alguien tras la máscara, pero Dioniso es la representación del devenir:

Dioniso lleva una máscara, como llevamos todos, pero él la usa como nadie:

debajo no está, no es, solo y siempre deviene otro, es lo otro, otro devenir de sí.

No otro de sí mismo:

nunca lo mismo de sí (2016: 138).

Por esto es que los tebanos no reconocen a Dioniso. Dioniso habla de Dioniso como si no fuera él. Y los demás no pueden aceptar que pueda ser Dioniso, puesto que tiene la máscara de otro, o la máscara de sí mismo, la cual es la máscara del instante que le está aconteciendo y por lo tanto no puede aferrarse al principio de identidad.

Mediante la imagen de la máscara, Mujica piensa el cambio. Dioniso es deconstrucción de la uniformidad y el estatismo. No hay ser. Se juega a ser. El juego lo es todo. Y en el juego las esencias son móviles. El dios aparece y su aparecer es apariencia. Por ello la existencia estética trabaja con el reino del disfraz para la fiesta, la palabra como construcción, el logos de la narración de quien va creándose a sí mismo en la medida en que cuenta historias.

Para Mujica, la máscara es revelación. Ella muestra lo que cada persona se pone para vivirse. Todo es máscara y creatividad. El ser humano se crea a sí en la medida en que usa la máscara que lo presenta ante sí mismo y ante el mundo. Por esto el saber definitivo es el del movimiento. O como lo plantea en Flecha en la niebla: "también la máscara es ícono, el embozo revela. El disfraz desnuda" (2014: 404).

\section{Danza}

La estética dionisíaca que presenta Mujica es una estética del cuerpo. En pocas páginas se repite la palabra cuerpo como en sus libros anteriores se hablaba con fre- 
cuencia del alma: el cuerpo no se repliega en sí, el cuerpo emerge, el cuerpo danza, el ritmo del cuerpo, el olvido del cuerpo, el cuerpo en su gratuidad, el cuerpo liberado, el cuerpo desde sí abierto a sí.

La danza es una palabra relativamente nueva en el universo poético de Mujica. En su Poesía completa de Vaso Roto aparece apenas cuatro veces. Y en La palabra inicial es una metáfora para describir la cuaternidad heideggeriana. Es en el Dioniso donde toma un protagonismo llamativo, apareciendo en 38 ocasiones y tiene el rol de actor principal en la presencia de Dioniso.

Para Mujica, la danza es el cuerpo en expansión, tratando de alcanzar lo que no es, de tocar los demás cuerpos, de imitar al universo en movimiento. La danza es representación móvil del giro de las estrellas y de la atracción de los animales para producir más vida, bajo el ímpetu de una música inquietante.

En este danzar hay mucho de erotismo. En la danza se conjugan vitalidad y arte. Deseo de ser y de fundirse en otro. Del cuerpo nacen cuerpos y la danza es la forma en la que el cuerpo imita lo que hacen la tierra y sus habitantes. Es el sendero a la fecundación, la invocación a los dioses de la fertilidad y la representación de la cópula. La danza de los cuerpos encarna al cosmos, pero también encarna al humano en la piel de otro humano; es un encuentro vital de la comunicación.

¿Dónde está Dioniso en medio de la danza? Esquilo escribe:

Él, que se ocupa de esto: de guiar a su cortejo en las danzas, de reír al son de la flauta, y de aquietar las penas, en cuanto aparece el fruto brillante del racimo en el banquete de los dioses, y cuando en los festejos de los hombres coronados de yedra la vasija de vino despliega sobre ellos el sueño (1998: 375-385).

Mujica responde:

Dioniso no danza.

Es la danza: se agita en los cuerpos.

En los cuerpos se danza.

En la danza los libra.

Es lo que en ella aflora y lo que en ella se deshoja.

(2016: 144).

Muchos textos de Mujica parecieran dejar de lado el erotismo y un lector atento extraña las presencias lúbricas en sus páginas. En su Dioniso emerge una sexualidad pletórica aunque no se la mencione de forma directa y gráfica. El placer late en medio de sátiros y ménades. La danza imita el vaivén de los cuerpos en movimiento de marea, el ritmo de la vida y la respiración agitada.

Dioniso es la danza de los contrarios, la fiesta en la que el rey legalista se viste de mujer y baila entre las ménades. Mujica pone en juego ambas realidades de todo 
ser humano y sociedad. Con Dioniso invita a reconocer lo reprimido y a vivir en el conflicto sin el cual la vida no fluye:

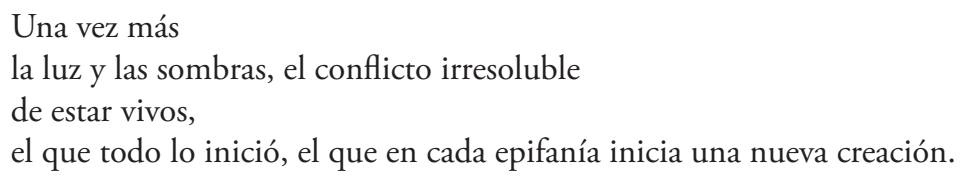

El que arraiga en las sombras

y brota hacia

la luz.

(2016: 123).

\section{Manía dionisíaca}

Aunque la manía dionisíaca podía ser vista por los no iniciados como peligrosa, también tenía para los griegos una dimensión artística e incluso cognoscitiva que podía ser liberadora:

En primer plano aparece el "frenesí" (manía), como elemento esencial del dios -comenta Giorgio Colli-. Esto significa un trauma del conocimiento, condicionado -como indican las alusiones textuales- por la música y por la ficción dramática (mimoi), es decir, por medio de elementos artísticos. Así surge una nueva visión de la realidad, basada en una ruptura con el conocimiento cotidiano (1995: 379).

Mujica valora a la manía dionisíaca como liberación, don del dios a sus adeptos. Y compara el desbordamiento que produce la locura con un río cuando sale de su cauce, cuando el yo rebasa.

En los santuarios donde se producía el vino más puro, como Theos y Andros (dios y hombre, por demás), era preciso beber en la fuente donde manaban; fuera de ella el vino era solamente agua. Para Mujica, no es el vino per se el que embriaga, sino la forma y la actitud del celebrante al beberlo.

Cuando el iniciado se dispone a que lo abierto se abra en él y lo expanda, aparece no sólo el efecto de la uva destilada sino que se manifiesta la deidad:

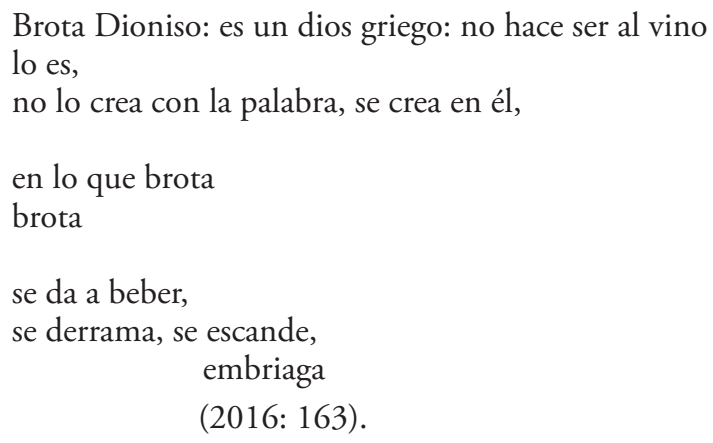


Mujica habla de dos experiencias de desbordamiento: el entusiasmo y el éxtasis. En el entusiasmo, el hombre y la mujer están poseídos dentro de sí, por algo que es más que ellos, un dios que impulsa e inspira. En el éxtasis hay algo más que el dios dentro de uno: es sentirse sacado de sí hacia una alteridad.

Mujica da énfasis a la dimensión extática de la manía, interpretándola desde una perspectiva existencial. En ella se diluyen el sujeto y el objeto. El cuerpo se siente uno con el mundo, o se siente mundo:

El ser humano, el existente, es su éx-tasis, su ser es ser fuera de sí, cumplir el ex de su ex-istencia (2016: 168).

Este afuera de sí lo pone en contacto con lo abierto, la desaparición de las rupturas porque todo es ruptura o hondura en la que se cae y desde la que brotan ramas. En varios libros de Mujica, como es el caso de Lo naciente (2007), lo abierto es una metáfora para la gran totalidad de todo lo ilimitado que ni siquiera cabe en la unidad. Lo abierto es la vida misma cuando aún no tiene nombres. La polis define las fronteras mediante murallas y leyes: dice hasta dónde se puede llegar. El éxtasis dionisíaco es la forma de lo abierto porque no hay tal limitación. El danzante quiere fundirse en la apertura. O como lo define Mujica en su Dioniso:

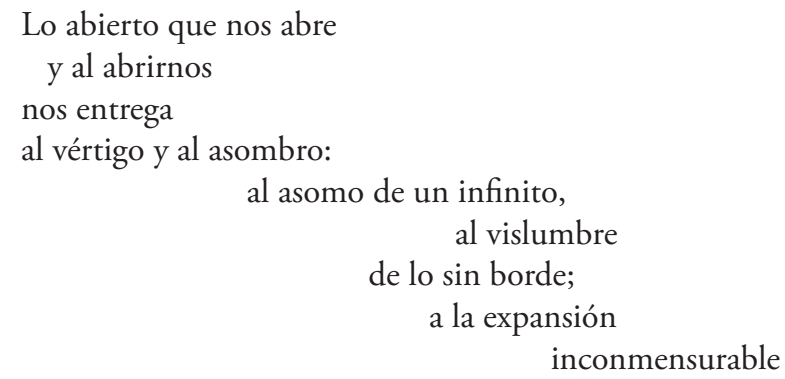

(2016: 154).

Mujica presenta los misterios de Dioniso en la vida griega, o lo que se conoce de ellos, pues eran secretos. Trae a colación una descripción que hace Mirtida de Antedón acerca de los ritos dionisíacos (2016: 188), de la cual destacamos algunas palabras clave que hacen eco en el ensayo del poeta: misterios de Dioniso, bosques nunca hollados, simpatía de los seres y las cosas, el ser caliente y húmedo, la conciencia del todo, el éxtasis, reírse de la muerte.

Esta imagen femenina fundiéndose con el mundo, plena de humedad y fuego, es valorada por Mujica como el desbordamiento de la vida espiritual (Zoé) sobre la vida corporal (Bios) mediante la plenitud de la carne y no en negación o huida. De 
modo que la katharsis trágica se realiza en la plena identificación de quien participa de la manía divina, yendo de éxtasis al reposo, sin separarse del sentimiento de pertenencia que le otorgó la plérosis báquica.

\section{Teatro}

Hacia el final del libro, Mujica presenta una relectura de Las Bacantes a su modo, es decir, pensando con imágenes y no con conceptos. Saca a la luz las imágenes más fuertes y sugestivas de la tragedia y luego propone una coda o reflexión sapiencial, como suele hacerlo en muchas ocasiones, especialmente en sus poemas.

Los personajes de la pieza teatral de Eurípides son presentados por Mujica como personificaciones de la existencia: Penteo y Dioniso. Penteo es la máscara para la ley, las raíces, el gobierno y la moral. La Paideia. La religión cívica. La aristocracia. La razón. La misoginia. La xenofobia.

Dioniso es la máscara teatral que representa al extranjero y la transformación. No el individuo queriendo diferenciarse sino una cofradía que celebra tomándose la mano. Arte. Irracionalidad o transracionalidad. Otras formas de pensar. Sentimiento. Alteridad. Desborde.

Penteo no danza. Dioniso es la danza. Penteo es el cazador de bacantes. Dioniso, animal sagrado, quiere matar al cazador.

Pero Penteo y Dioniso son primos, casi hermanos. La razón y el arte se tocan las entrańas. La gracia es la contracara de la ley, ambas pertenecen a una misma superficie. Nietzsche establece la polaridad en el Olimpo y los santuarios, entre Apolo y Dioniso; Mujica, ceñido a Eurípides, la dibuja en el argumento trágico, haciendo a Penteo y Dioniso mucho más comparables a la condición humana.

Mujica lleva a sus lectores al Monte Citerón, lugar del sacrificio. Allí introduce a los personajes femeninos, las bacantes, representadas en Ágave, madre de Penteo. El rey, mientras tanto, las acecha, como el invasor a la mujer que busca violar. Las bacantes, anteriormente "atadas a la casa y la cocina", se transforman en cazadoras que matan, desplegando todo su odio hacia el varón que las somete.

La tragedia se presenta como un juego infantil y letal. Mujica se detiene a reflexionar sobre la imagen de una madre poseída desmembrando a su hijo:

Ágave, furiosa, lo desgarra, sus manos lo destrozan, le arranca la cabeza a su propio hijo, lo ve como un animal más, lo ve.

No reconoce a su hijo como su hijo no reconoce

a Dioniso como dios, no se abre a él,

y -aprenderá trágicamente, aprenderá padeciéndolo- que lo que se opone a transformarse se expone a quebrarse,

lo rígido a partirse, 
lo sólido a hundirse

(2016: 184).

Así deja en alto el poderío de la vida y de la naturaleza sobre la resistencia de las estructuras que pretenden controlar lo sagrado y la moral. En Dioniso, lo sagrado es inmoral, inconmensurable. Él despedaza aquello que no entra en la danza del misterio. La dulzura y la crueldad juegan a la ronda.

Mujica no ve la tragedia en tonalidad funesta sino, como lo hacían los antiguos griegos, al modo de una katharsis literaria. La vida ha triunfado cuando se personificó en el dios. Dioniso reconquista Tebas a través de la locura y se convierte en el dios de la ciudad; o más bien convierte al otro, a la alteridad, a los seres marginales, en rostros de lo sagrado:

Ahora Dioniso se constituye en dios. Una divinización desde abajo. Ahora en sus festividades, sus cultos, sus veneraciones,

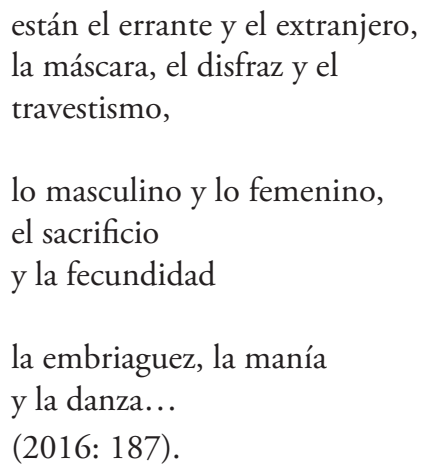

\section{Creatividad}

Mujica cierra su libro inclinando la imagen y máscara del dios itinerante, el dios otro, el dios loco, hacia la dimensión de la creatividad. Este el misterio dionisíaco para el poeta, el hacedor. Su ritual descansa en ser poseído del silencio o la palabra, en la creación:

Dioniso es el encuentro

$$
\text { embriagador }
$$

con la creatividad:

ni la piel toca ni es tocada,

se disuelve la dualidad

se aúna estremecimiento

(2016: 197).

En esto se ha cifrado el libro del escritor argentino: Dioniso como la obra teatral que se vive en nosotros, abriéndose a lo abierto en la medida en que nos dejamos 
poseer del dios; y también la máscara y danza del arte que viene desde afuera y nos posee sin negarnos, sin hacer a un lado nuestra carne o sacrificar el contacto de nuestra piel con el todo. Es la creatividad en carne viva y la carne viva como creatividad.

De este modo Mujica evoca la imagen que despliega en el prólogo de Lo naciente, cuando propone al dios como creación humana de la creatividad creándose y creándonos. El dios que permite al hombre y la mujer salir de sí mediante el éxtasis de la vida y del arte para volver a sí de modo diferente, relacionándose con el mundo mediante un panteísmo estético que le da nuevas superficies a la existencia:

Sea que un dios creó al hombre a su imagen y semejanza o el hombre imaginó a ese dios a semejanza suya, lo cierto es que cuando el ser humano comenzó a contarse el inicio del mundo en el que se encontró viviendo, dio como atributo primordial a ese dios el ser creador, dijo, intuyó, que crear es el acto más inicial que un humano o un dios puede realizar, o el acto en que uno y otro son un mismo acontecer, una misma fecundidad (2014b: 149).

Para Mujica hablar de Dioniso es también hablar del ser humano y de lo que lo desborda. Porque hablar de un dios es hablar de lo que preocupa al hombre. Toda teogonía es una antropología. Al cantar a los dioses, nos cantamos a nosotros mismos y somos cantados por el canto. La máscara divina de la poética de Mujica posee el nombre de la tradición del misterio inacabado: Dioniso, la morphé, la forma en cambio inacabado:

Los pies descalzos

son un sendero

\author{
y cerrar los ojos \\ siempre fue atajo: \\ lo que buscamos no existe, \\ viviéndolo lo creamos
}

(2016: 25).

\title{
Referencias
}

Colli, Giorgio (1995). La sabiduría griega. Dionisos, Apolo, Eleusis, Orfeo, Museo, Hiperbóreos, Enigma. Madrid: Trotta.

Detienne, Marcel (2013). Dioniso a cielo abierto. Los mitos del dios griego del desenfreno. Barcelona: Gedisa.

Graves, Robert (2017). Los mitos griegos 1. Madrid: Alianza.

Eurípides (1998). Tragedias III. Traducción de Carlos García Gual y Luis Alberto de Cuenca y Prado. Madrid: Gredos.

Hesíodo (1978). Teogonía. Introducción, traducción y notas de Aurelio Pérez Jiménez y Alfonso Martínez Díez. Madrid: Gredos. 
Mujica, Hugo (2016). Dioniso. Eros creador y mística pagana. Buenos Aires: El hilo de Ariadna.

- (2014a). Del crear y lo creado 2. Prosa selecta 1: Ensayos. México: Vaso Roto.

—. (2014b). Del crear y lo creado 3. Prosa selecta 1: Ensayos. México: Vaso Roto.

- (2013). Del crear y lo creado 1. Poesía completa. 1983-2011. Madrid / México: Vaso Roto

Nietzsche, Friedrich (1988). Die Geburt der Tragödie/Unzeitgemäße Betrachtungen / Nachgelassene Schriften. Herausgeben von Giorgio Colli und Mazzino Montinari, Bd. 1. München: de Gruyter. 